\title{
Phase 1 study of the MDM2 antagonist R06839921 in patients with acute myeloid leukemia
}

\author{
Geoffrey L. Uy ${ }^{1} \cdot$ Sarit Assouline ${ }^{2} \cdot$ Anne-Marie Young $^{3} \cdot$ Steven Blotner ${ }^{4} \cdot$ Brian Higgins $^{4} \cdot$ Lin-Chi Chen $^{4} \cdot$ Karen Yee $^{5}$
}

Received: 2 January 2020 / Accepted: 15 January 2020 / Published online: 4 February 2020

(C) The Author(s) 2020

\begin{abstract}
In acute myeloid leukemia (AML), TP53 mutations and dysregulation of wild-type p53 is common and supports an MDM2 antagonist as a therapy. RO6839921 is an inactive pegylated prodrug of the oral MDM2 antagonist idasanutlin (active principle $[\mathrm{AP}]$ ) that allows for IV administration. This phase 1 monotherapy study evaluated the safety, pharmacokinetics, and pharmacodynamics of RO6839921 in patients with AML. Primary objectives identified dose-limiting toxicities (DLTs) and maximum tolerated dose (MTD). Secondary objectives assessed pharmacokinetic, pharmacodynamic, and antileukemic activity. A total of 26 patients received 120-300 mg AP of idasanutlin. The MTD was $200 \mathrm{mg}$, with DLTs at 250 (2/8 patients) and $300 \mathrm{mg}(2 / 5)$. Treatment-related adverse events in $>20 \%$ of patients were diarrhea, nausea, vomiting, decreased appetite, and fatigue. Six deaths $(23.1 \%)$ occurred, all unrelated to treatment. Pharmacokinetics showed rapid and near-complete conversion of the prodrug to AP and dose-proportional exposure across doses. Variability ranged from 30\%-47\% (22\%-54\% for idasanutlin). TP53 was 21 (87.5\%) wild-type and 3 mutant $(12.5 \%)$. The composite response rate (complete remission [CR], CR with incomplete hematologic recovery/ morphological leukemia-free state [CRi/MLFS], or CR without platelet recovery [CRp]) was 7.7\%. Antileukemic activity (CR, CRi/MLFS, partial response, hematologic improvement/stable disease) was observed in 11 patients (disease control rate, 42\%): 10/11 were TP53 wild-type; 1 had no sample. p53 activation was demonstrated by MIC-1 induction and was associated with AP exposure. There was not sufficient differentiation or improvement in the biologic or safety profile compared with oral idasanutlin to support continued development of RO6839921. NCT02098967.
\end{abstract}

Keywords Acute myeloid leukemia $\cdot$ MDM2 $\cdot$ Idasanutlin $\cdot$ Safety

Support for third-party writing assistance for this manuscript, furnished by writer Denise Kenski, PhD, CMPP, of Health Interactions, Inc, was provided by F. Hoffmann-La Roche Ltd. and Genentech, Inc.

Geoffrey L. Uy

guy@wustl.edu

1 Division of Oncology, Washington University School of Medicine, St Louis, MO, USA

2 Jewish General Hospital, Montreal, QC, Canada

3 Pharma Research and Early Development, Roche Innovation Center, Welwyn Garden City, UK

4 Pharma Research and Early Development, Roche Innovation Center, New York, NY, USA

5 Princess Margaret Cancer Centre, Toronto, ON, Canada

\section{Introduction}

The $\mathrm{p} 53$ protein is a growth-suppressive and pro-apoptotic protein that plays a central role in the protection of cells from tumor development. [1, 2] In normal cells, a close relationship exists between $\mathrm{p} 53$ and its primary regulator, murine double minute 2 (MDM2), which controls both $\mathrm{p} 53$ expression and degradation. MDM2 regulates $\mathrm{p} 53$ through a negative feedback loop. When nuclear p53 levels are elevated, they activate the transcription of the $M D M 2$ gene; this allows MDM2 to bind to $\mathrm{p} 53$, blocking its transactivation domain and targeting p53 for ubiquitin-dependent degradation. [1-3]

The p53 signaling pathway is frequently inactivated in acute myeloid leukemia (AML). The TP53 mutation rate is $<10 \%$ of cases of de novo AML [4]; however, inactivation of wild-type p53 occurs in many patients with AML by alternative mechanisms, including overexpression of MDM2, in order to allow proliferation and leukemogenesis. [5] Therefore, 
treatment with an MDM2 antagonist is a therapeutic option to restore p53 activity in these cases. $[1,6]$ MDM2 antagonists block p53-MDM2 binding, stabilize p53, and activate p53 signaling, thereby inducing cell cycle arrest and apoptosis. Idasanutlin, an oral MDM2 antagonist of the nutlin family of compounds, [6, 7] is being evaluated in phase 1 to 3 clinical trials in patients with solid and hematologic malignancies. [8, 9] In clinical trials in patients with AML who received MDM2 antagonists, MDM2 gene expression was related to clinical response. [10-12]

RO6839921 is an inactive pegylated prodrug of idasanutlin that allows for the solubility needed for IV administration, with the goals of improving exposure variability and pharmacokinetic parameters, reducing gastrointestinal toxicity in the absence of prophylaxis, and potentially improving efficacy compared with oral idasanutlin. The active principle (AP; idasanutlin) is released upon cleavage of its pegylated tail by esterases in the blood. IV-administered RO6839921 showed antitumor activity at nontoxic doses in established osteosarcoma and AML xenograft models in immunocompromised mice. [13] These nonclinical pharmacology results supported further evaluation of RO6839921 in clinical studies. This phase 1 study evaluated the safety, tolerability, pharmacokinetics, and pharmacodynamics of RO6839921 in patients with AML.

\section{Methods}

\section{Patients}

This phase 1 study (NCT02098967) was an open-label, first-in-human, multicenter, dose-escalation study of RO6839921 in patients with solid tumors and in patients with AML; results for solid tumors will be reported independently. Patients aged $\geq 18$ years with relapsed/ refractory AML, untreated AML with antecedent hematologic disorder, or high-risk de novo AML as defined by the 2010 European LeukemiaNet (ELN) criteria with Eastern Cooperative Oncology Group performance status of $\leq 2$ were eligible. [14] Patients with central nervous system leukemia or any severe and/or uncontrolled medical conditions or other conditions that could affect their participation were excluded. The study was conducted in accordance with the principles of the International Conference on Harmonization Good Clinical Practice guidelines. All procedures performed in studies involving human participants were in accordance with the ethical standards of the institutional and/or national research committees at the study sites and with the 1964 Declaration of Helsinki and its later amendments or comparable ethical standards. Informed consent was obtained from all participants included in the study.

\section{Study design}

RO6839921 was administered as an IV infusion over approximately $1 \mathrm{~h}$ once daily for 5 days every 28 days. Dose escalation was performed using a modified rolling 6 design initiated at or below the dose at which grade $\geq 2$ hematologic toxicity or projected efficacious exposure was reached in the solid tumor arm (120 mg AP). [15] Based on this design, the doses tested were 120, 200, 250, and $300 \mathrm{mg}$ (in $\mathrm{mg}$ of AP).

The primary objectives of the study were to determine the maximum tolerated dose (MTD) and recommended phase 2 dose of RO6839921 and to characterize dose-limiting toxicities (DLTs) and the overall safety profile. The secondary objectives were to determine the pharmacokinetic parameters of RO6839921 and the AP and to assess the pharmacodynamic effects of RO6839921 and clinical responses. Treatment continued until disease progression, unacceptable toxicity, withdrawal of consent, or investigator discretion.

\section{Assessments and analysis}

Patients receiving $\geq 1$ dose of RO6839921 were considered evaluable for safety. Adverse events (AEs) were graded according to the National Cancer Institute Common Terminology Criteria for Adverse Events (version 4.03).

The DLT-evaluable population was defined as all patients who received $\geq 80 \%$ of study medication and completed the first 28-day treatment cycle. In addition, patients who had a DLT but did not meet the minimum dosing requirements were considered evaluable for DLTs. DLTs were assessed during the first treatment cycle (28 days) and included prolonged grade 4 neutropenia and prolonged grade $3 / 4$ thrombocytopenia lasting $\geq 42$ days from the start of the cycle in the absence of evidence of active AML as well as clinically significant grade 3 to 5 nonhematologic toxicity. The MTD was defined as the highest dose level tested with 0 to 1 DLT in a cohort of 6 .

Plasma pharmacokinetic assessments of RO6839921 and AP concentrations were conducted in all patients during the first cycle of treatment on the first and fifth days of dosing immediately before dosing and at multiple postdose time points using a validated liquid chromatographytandem mass spectrometry method, with pharmacokinetic parameters estimated using standard noncompartmental methods. Assessment of macrophage inhibitory cytokine 1 (MIC-1) protein levels was measured in serum before and after administration of RO6839921 using an enzymelinked immunosorbent assay. TP53 mutation status was measured by next-generation sequencing at baseline.

The efficacy population was defined as all patients who received $\geq 80 \%$ of study medication and completed the first 28-day treatment cycle. Efficacy was evaluated on 
Table 1 Baseline demographic and clinical characteristics

\begin{tabular}{|c|c|c|c|c|c|}
\hline Characteristics & $\begin{array}{l}120 \mathrm{mg} \\
\mathrm{AP} \\
(n=6)\end{array}$ & $\begin{array}{l}200 \mathrm{mg} \\
\mathrm{AP} \\
(n=7)\end{array}$ & $\begin{array}{l}250 \mathrm{mg} \\
\mathrm{AP} \\
(n=8)\end{array}$ & $\begin{array}{l}300 \mathrm{mg} \\
\mathrm{AP} \\
(n=5)\end{array}$ & $\begin{array}{l}\text { Total } \\
(N=26)\end{array}$ \\
\hline Male, $\mathrm{n}(\%)$ & $3(50.0)$ & $5(71.4)$ & $3(37.5)$ & 0 & $11(42.3)$ \\
\hline Median age (range), years & $50(24-73)$ & $58(47-74)$ & $74(64-80)$ & $49(33-71)$ & $\begin{array}{l}65 \\
(24-80)\end{array}$ \\
\hline \multicolumn{6}{|l|}{ ECOG PS, n (\%) } \\
\hline 0 & $4(67)$ & $2(29)$ & $1(13)$ & $1(20)$ & $8(31)$ \\
\hline 1 & $2(33)$ & $5(71)$ & $7(88)$ & $4(80)$ & $18(69)$ \\
\hline \multicolumn{6}{|l|}{ ELN risk at diagnosis, $\mathrm{n}(\%)$} \\
\hline Favorable & 0 & $1(14)$ & $1(13)$ & 0 & $2(8)$ \\
\hline Intermediate 1 & 0 & $3(43)$ & $3(38)$ & $1(20)$ & $7(27)$ \\
\hline Intermediate 2 & $1(17)$ & $2(29)$ & $1(13)$ & $1(20)$ & $5(19)$ \\
\hline Adverse & $5(83)$ & $1(14)$ & $3(38)$ & $3(60)$ & $12(46)$ \\
\hline $\begin{array}{l}\text { Antecedent hematologic disorder, } \mathrm{n} \\
(\%)^{*}\end{array}$ & $1(17)$ & 0 & $3(38)$ & $2(40)$ & $6(23)$ \\
\hline \multirow{2}{*}{\multicolumn{6}{|c|}{$\begin{array}{l}\mathrm{n}(\%)^{\dagger} \\
\text { No. of prior regimens, } \mathrm{n}(\%)\end{array}$}} \\
\hline & & & & & \\
\hline 0 & $1(16.7)$ & 0 & $2(25)$ & $1(20)$ & $4(15.4)$ \\
\hline 1 & $1(16.7)$ & $2(28.6)$ & $3(37.5)$ & $1(20)$ & $7(26.9)$ \\
\hline 2 & $2(33.3)$ & $2(28.6)$ & $3(37.5)$ & $2(40)$ & $9(34.6)$ \\
\hline 3 & $1(16.7)$ & $2(28.6)$ & 0 & $1(20)$ & $4(15.4)$ \\
\hline 4 & $1(16.7)$ & $1(14.3)$ & 0 & 0 & $2(7.7)$ \\
\hline Prior allogeneic transplant, $\mathrm{n}(\%)$ & $1(17)$ & $4(57)$ & $1(13)$ & $1(20)$ & $7(27)$ \\
\hline \multicolumn{6}{|l|}{ Response to prior therapy ${ }^{\ddagger}$} \\
\hline No prior therapy & $1(17)$ & 0 & $2(25)$ & $1(20)$ & $4(15)$ \\
\hline Refractory & $2(33)$ & $2(29)$ & $3(38)$ & $3(60)$ & $10(38)$ \\
\hline $\mathrm{CR} 1<3$ months & $1(17)$ & $1(14)$ & 0 & 0 & $2(8)$ \\
\hline CR1 3- 12 months & $2(33)$ & $4(57)$ & $2(25)$ & $1(20)$ & $9(35)$ \\
\hline CR1 > 12 months & 0 & 0 & $1(13)$ & 0 & $1(13)$ \\
\hline \multicolumn{6}{|l|}{ TP53 status } \\
\hline Not evaluable & $1(17)$ & $1(14)$ & 0 & 0 & $2(8)$ \\
\hline Evaluable & $5(83)$ & $6(86)$ & $8(100)$ & $5(100)$ & $24(92)$ \\
\hline Wild type & $5(100)$ & $5(83)$ & $8(100)$ & $3(60)$ & $21(81)$ \\
\hline Mutant & 0 & $1(17)$ & 0 & $2(40)$ & $3(12)$ \\
\hline
\end{tabular}

$A P$ active principle, $C R 1$ complete remission with first treatment received, ECOG PS Eastern Cooperative Oncology Group performance status, ELN European LeukemiaNet

*Includes chronic myelomonocytic leukemia, myelodysplastic syndromes, and essential thrombocythemia

${ }^{\dagger}$ Prior cancer includes lymphoma $(n=4)$, prostate cancer, and breast cancer

${ }^{\ddagger}$ A first complete remission/complete remission without platelet recovery $<12$ months is associated with poor response rates in relapse day 1 of every cycle starting with cycle 2 . A composite response rate was calculated by determining the number of patients who achieved a best response (complete remission $[\mathrm{CR}], \mathrm{CR}$ without platelet recovery $[\mathrm{CRp}]$, or $\mathrm{CR}$ with incomplete recovery of peripheral counts [CRi]/morphological leukemia-free state [MLFS]) divided by the total number of patients in the efficacy population. Additional outcomes were partial response with $\geq 50 \%$ decrease in bone marrow blasts, hematologic improvement measures, and disease progression. Hematologic improvement/stable disease (HI/SD) was defined as decreased peripheral blast percentage, decreased frequency of transfusions, and/or improvement in peripheral cell counts in the absence of $\mathrm{CR}$ in the marrow and were considered by Investigators and Sponsor on a case by case basis for continuation of treatment. 
Table 2 Summary of adverse events per MedDRA preferred term $(\geq 30 \%$ of patients for any adverse events or $\geq 5 \%$ treatmentrelated adverse events)

\begin{tabular}{|c|c|c|c|c|}
\hline \multirow[t]{2}{*}{ Patients with an AE, $\mathrm{n}(\%) N=26$} & \multicolumn{2}{|l|}{ All AEs } & \multicolumn{2}{|c|}{ Treatment-related AEs } \\
\hline & Any grade & Grade $\geq 3$ & Any grade & Grade $\geq 3$ \\
\hline Nausea & $15(57.7)$ & 0 & $13(50.0)$ & $3(11.5)$ \\
\hline Decreased appetite & $14(53.8)$ & 0 & $8(30.8)$ & 0 \\
\hline Febrile neutropenia & $14(53.8)$ & $14(53.8)$ & $3(11.5)$ & 0 \\
\hline Hypomagnesemia & $13(50.0)$ & 0 & $1(3.8)$ & 0 \\
\hline Diarrhea & $13(50.0)$ & $1(3.8)$ & $13(50.0)$ & $1(3.8)$ \\
\hline Hypokalemia & $11(42.3)$ & $6(23.1)$ & 0 & 0 \\
\hline Vomiting & $10(38.5)$ & 0 & $9(34.6)$ & 0 \\
\hline Constipation & $10(38.5)$ & 0 & 0 & 0 \\
\hline Fatigue & $10(38.5)$ & $1(3.8)$ & $7(26.9)$ & $1(3.8)$ \\
\hline Stomatitis & $9(34.6)$ & $3(11.5)$ & $5(19.2)$ & $1(3.8)$ \\
\hline Hypotension & $9(34.6)$ & 0 & 0 & 0 \\
\hline Edema peripheral & $9(34.6)$ & 0 & $1(3.8)$ & 0 \\
\hline Hypophosphatemia & $8(30.8)$ & $3(11.5)$ & 0 & 0 \\
\hline Hyperphosphatemia & $8(30.8)$ & 0 & 0 & 0 \\
\hline Abdominal pain & $8(30.8)$ & $1(3.8)$ & $5(19.2)$ & 0 \\
\hline Epistaxis & $5(19.2)$ & $2(7.7)$ & $3(11.5)$ & $2(7.7)$ \\
\hline Dyspepsia & $4(15.4)$ & 0 & $2(7.7)$ & 0 \\
\hline Alopecia & $4(15.4)$ & 0 & $4(15.4)$ & 0 \\
\hline
\end{tabular}

$A E$ adverse event, MedDRA Medical Dictionary for Regulatory Activities

\section{Results}

\section{Patient disposition and characteristics}

This study was conducted at 6 sites in the United States and Canada between April 2014 and May 2018. A total of 26 patients with AML were treated at 4 doses: $120 \mathrm{mg}$ AP $(n=$ 6), $200 \mathrm{mg} \mathrm{AP}(n=7), 250 \mathrm{mg} \mathrm{AP}(n=8)$, and $300 \mathrm{mg} \mathrm{AP}$ $(n=5)$. Patients received a median of 5 doses (range, 4-10). The median treatment duration was 5 days (range, 4-86 days), and the median cumulative dose was $1225 \mathrm{mg}$ (range, 600$3000 \mathrm{mg}$ ). Treatment was discontinued in 10 patients (38.5\%) due to progression of disease, 9 patients (34.6\%) due to physician decision (perceived lack or loss of clinical benefit), and 7 patients $(26.9 \%)$ due to AEs.

The median age was 65 years (Table 1). The majority of patients had an ELN intermediate 2 [14] or adverse risk and had an Eastern Cooperative Oncology Group performance status of 0 or 1 . Half the patients had prior cancer, and $81 \%$ had wild-type TP53 status.

\section{DLT and MTD determination}

All 26 patients were evaluable for DLTs. Four patients (15.4\%) experienced DLTs: 2 in the 300-mg cohort experienced 2 DLTs (colitis [grade 3, serious] and electrocardiogram QT interval prolonged [grade 4, serious]) and 2 in the 250-mg cohort experienced 2 DLTs (diarrhea [grade 3] and stomatitis [grade 3]). The MTD (defined as the highest dose level tested with $0-1$ DLT in a cohort of 6 patients) in patients with AML was $200 \mathrm{mg}$ AP (0 DLTs in 7 patients).

\section{Safety}

All 26 patients received $\geq 1$ dose of R06839921 and were therefore considered safety evaluable. The most common AEs were nausea (57.7\%), decreased appetite and febrile neutropenia (53.8\% each), diarrhea and hypomagnesemia (50.0\% each), hypokalemia (42.3\%), constipation, fatigue, and vomiting (38.5\% each), hypotension, peripheral edema, and stomatitis (34.6\% each), and abdominal pain, hypophosphatemia, and hyperphosphatemia (30.8\% each) (Table 2). All but 1 patient had AEs of grade $\geq 3$ (25 patients [96.2\%]), and the most common were febrile neutropenia (53.8\% of patients), hypokalemia (23.1\%), lung infection (15.4\%), and hypophosphatemia and stomatitis (11.5\% each). Most patients experienced a treatmentrelated AE (24 patients [92.3\%]). The most common treatment-related AEs were diarrhea and nausea $(50.0 \%$ each), vomiting (34.6\%), decreased appetite (30.8\%), and fatigue $(26.9 \%)$ (Table 2). Serious AEs occurred in 22 patients $(84.6 \%)$ (Table 3$)$. The most common was febrile neutropenia in 13 patients $(50.0 \%)$.

Seven patients (26.9\%) experienced 8 AEs leading to withdrawal of study treatment ( 3 patients each in the 250 - and 300 mg cohorts, 1 patient in the 200-mg cohort). One patient (250- 
Table 3 Summary of serious adverse events (per MedDRA preferred term)

\begin{tabular}{lll}
\hline Patients with an SAE, $\mathrm{n}(\%) N=26$ & All AEs & Study drug-related AEs \\
\hline Febrile neutropenia & $13(50.0)$ & $2(7.7)$ \\
Lung infection & $3(11.5)$ & 0 \\
Aspergillus infection & $1(3.8)$ & 0 \\
Bacterial sepsis & $1(3.8)$ & 0 \\
Cellulitis & $1(3.8)$ & 0 \\
Enterobacter bacteremia & $1(3.8)$ & 0 \\
Enterobacter infection & $1(3.8)$ & 0 \\
Enterococcal sepsis & $1(3.8)$ & 0 \\
Proctitis herpes & $1(3.8)$ & 0 \\
Pseudomonal bacteremia & $1(3.8)$ & 0 \\
Sepsis & $1(3.8)$ & 0 \\
Colitis & $1(3.8)$ & $1(3.8)$ \\
Gastritis & $1(3.8)$ & $1(3.8)$ \\
Acute coronary syndrome & $1(3.8)$ & 0 \\
Acute cardiac failure & $1(3.8)$ & 0 \\
Myocardial ischemia & $1(3.8)$ & 0 \\
Blood creatinine increased & $1(3.8)$ & $1(3.8)$ \\
Electrocardiogram QT interval prolonged & $1(3.8)$ & $1(3.8)$ \\
Dyspnea & $1(3.8)$ & 0 \\
Pyrexia & $1(3.8)$ & 0 \\
Menorrhagia & $1(3.8)$ & 0 \\
Thrombosis & $1(3.8)$ & 0 \\
\hline
\end{tabular}

$A E$ adverse event, MedDRA Medical Dictionary for Regulatory Activities, SAE serious adverse event mg cohort) reported 2 AEs of acute cardiac failure and sepsis; all other AEs (acute coronary syndrome, acute cardiac failure, bacterial sepsis, diarrhea, and pyrexia) were experienced by 1 patient each. Five patients (19.2\%) experienced dose interruptions: 2 in the $120-\mathrm{mg}$ cohort due to febrile neutropenia and aspergillus infection, respectively, both grade $3 ; 2$ in the 200$\mathrm{mg}$ cohort due to febrile neutropenia (1 patient had 1 febrile neutropenia event and 1 patient had 2 febrile neutropenia events); and 1 in the 250-mg cohort due to increased blood creatinine and decreased renal creatinine clearance, both grade 2.

Six deaths $(23.1 \%)$ were reported during the study. Four deaths were due to progressive disease or relapse. Two deaths resulted from AEs with a fatal outcome (acute coronary syndrome and bacterial sepsis); both of these were judged to be unrelated to the study medication.

\section{Pharmacokinetics}

Mean plasma prodrug concentration-time profiles following RO6839921 administration of the AP are presented in Fig. 1a; pharmacokinetic parameters for RO6839921 and the AP are summarized in Tables 4 and 5. The dose-exposure relationship for the AP on days 1 and 5 was approximately linear and dose proportional (Fig. 1b and c). For the 200-, 250-, and 300-mg cohorts, the mean 24-h area under the plasma concentrationtime curve on day 5 was above the target exposure of $100 \mathrm{~h} \cdot \mu \mathrm{g} / \mathrm{mL}$ for RO6839921 (Table 4) and the AP (Table 5) based on preclinical studies. [13]

\section{Biomarkers and pharmacodynamics}

MIC-1, a secretory protein that is strongly upregulated by activated $\mathrm{p} 53$, can be detected in the blood of mice bearing human tumor xenografts after treatment with doxorubicin, a genotoxic p53 activator of the MDM2 antagonist nutlin-3. [16] Therefore, MIC-1 could have utility as a progressive disease biomarker for RO6839921. In previous trials that included patients with AML, concentrationrelated pharmacodynamic biomarker activity of the p53 pathway was demonstrated by increases in MIC-1 levels. [12] In this study, the pharmacodynamic association of change in MIC-1 levels from baseline correlated with steady-state AP exposure (Fig. 2).

Bone marrow samples from 22 patients were evaluated for TP53 status, and 5 (21\%) had $\geq 1$ mutation. One patient had $>1$ mutation detected. The 2 patients who had a best response of CR/CRi or MLFS did not have TP53 mutations; however, 1 patient who had HI/SD as a first response had a mutation. 
Fig. 1 Pharmacokinetic analyses. a Mean plasma idasanutlin (AP) concentrationtime profiles following RO6839921 (prodrug) administration; b AP doseexposure relationship on days 1 and 5 for absolute AUC; $\mathbf{c}$ AP dose-exposure relationship on days 1 and 5 for dose-normalized AUC. AP, active principle; DN, dose-normalized; $\mathrm{AUC}_{0-24}, 24-\mathrm{h}$ area under the plasma concentration-time curve

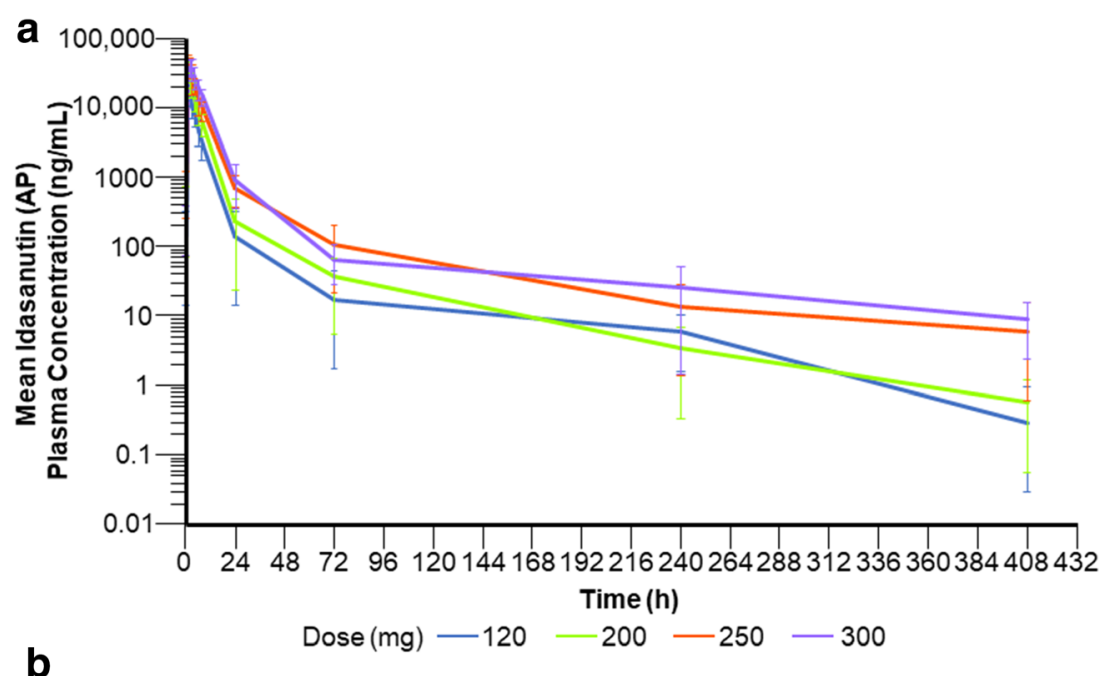

b

Cycle 1 Day 1

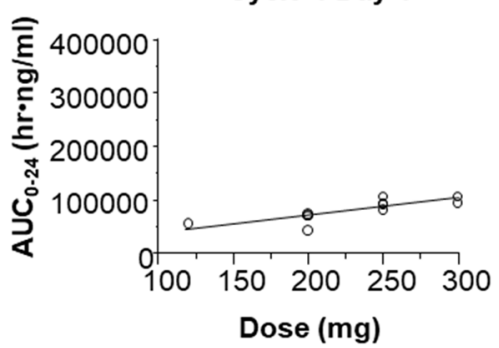

C

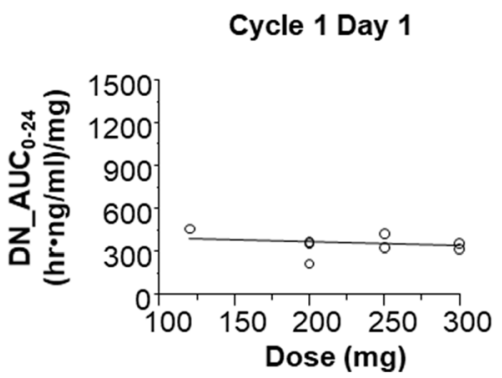

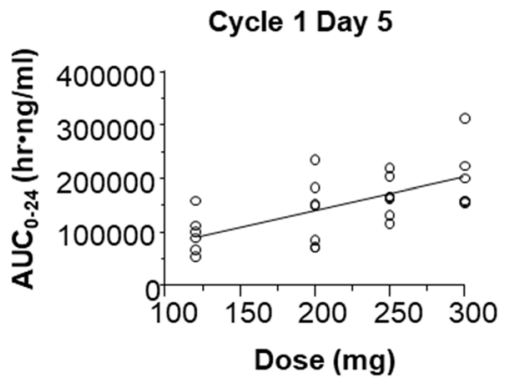

Cycle 1 Day 5

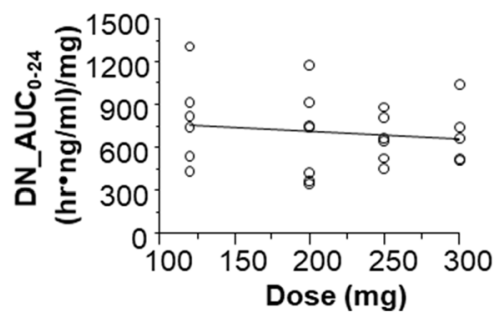

\section{Efficacy}

The composite response rate (CRc; $\mathrm{CR}, \mathrm{CRp}$, or CRi/MLFS) was $7.7 \%$ ( 2 patients): 1 patient each in the $250-\mathrm{mg}(\mathrm{CR})$ and 300-mg (CRi/MLFS) cohorts (Table 6). Two patients (7.7\%) achieved a partial response: 1 patient each in the 200- and 250-mg cohorts. Seven patients $(26.9 \%)$ had HI/SD. The disease control rate (CRc, partial response, or HI/SD) was $42 \%$ (11 of 26 patients). Five patients were not evaluated: 4 due to AEs and 1 due to physician decision to administer hydroxyurea off protocol because of increasing white count. Of patients who demonstrated antileukemic activity (CR, CRi/MLFS, partial response, or HI/SD), the best change in bone marrow blasts from baseline was varied (Fig. 3a). The median overall duration of antileukemic activity (CR, CRp, CRi/MLFS, partial response, or HI/SD) was 58 days (range, 23-206 days; Fig. 3b).

\section{Discussion}

RO6839921 is a potent pegylated prodrug and selective new-generation antagonist of the p53-MDM2 interaction for IV administration. RO6839921 is metabolized to idasanutlin, which then binds selectively to the p53 site on the surface of the MDM2 molecule in vitro with high affinity and can effectively displace p53 from MDM2, leading to stabilization and accumulation of the $\mathrm{p} 53$ protein and activation of the p53 pathway. [13] In this phase 1 study in patients with AML, RO6839921 demonstrated a pharmacokinetic, pharmacodynamic, and safety profile similar to that of idasanutlin, with evidence of antileukemic activity.

RO6839921 was developed to decrease variability in exposure observed with idasanutlin and allow expansion into indications such as pediatrics or cases where patients 


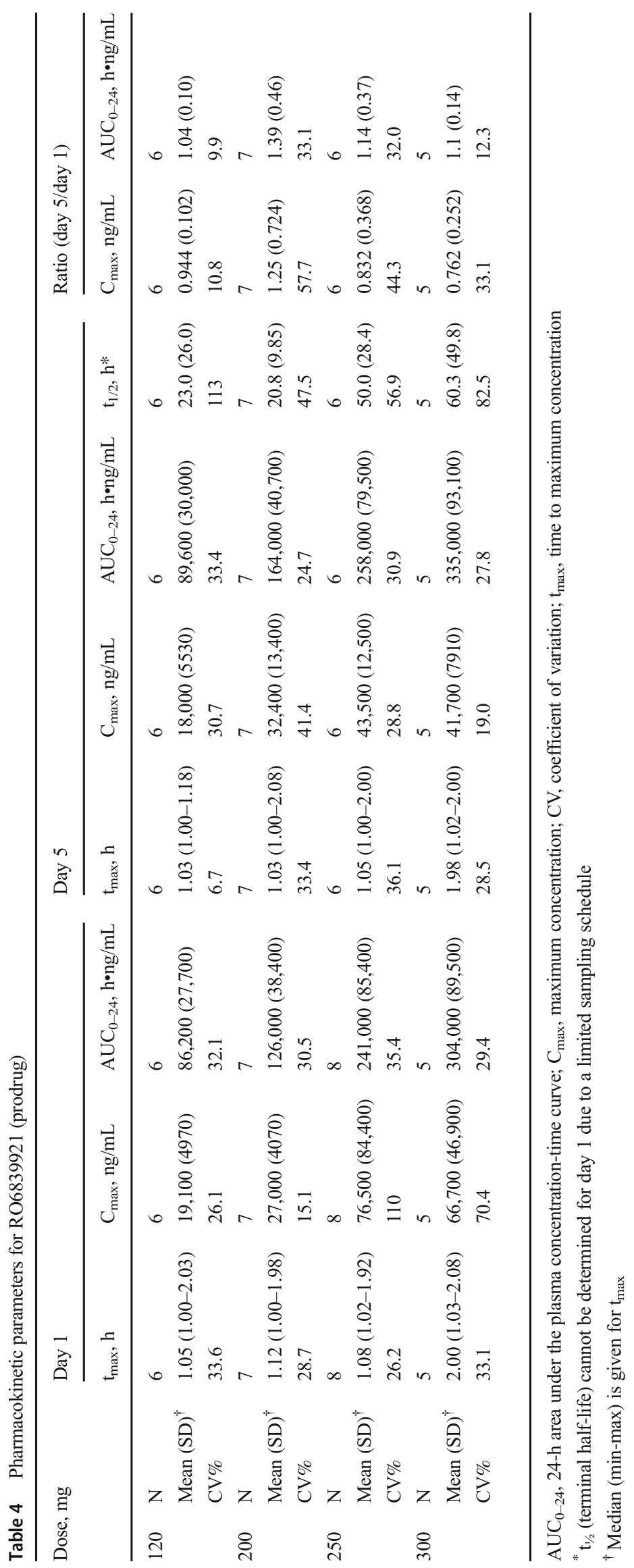




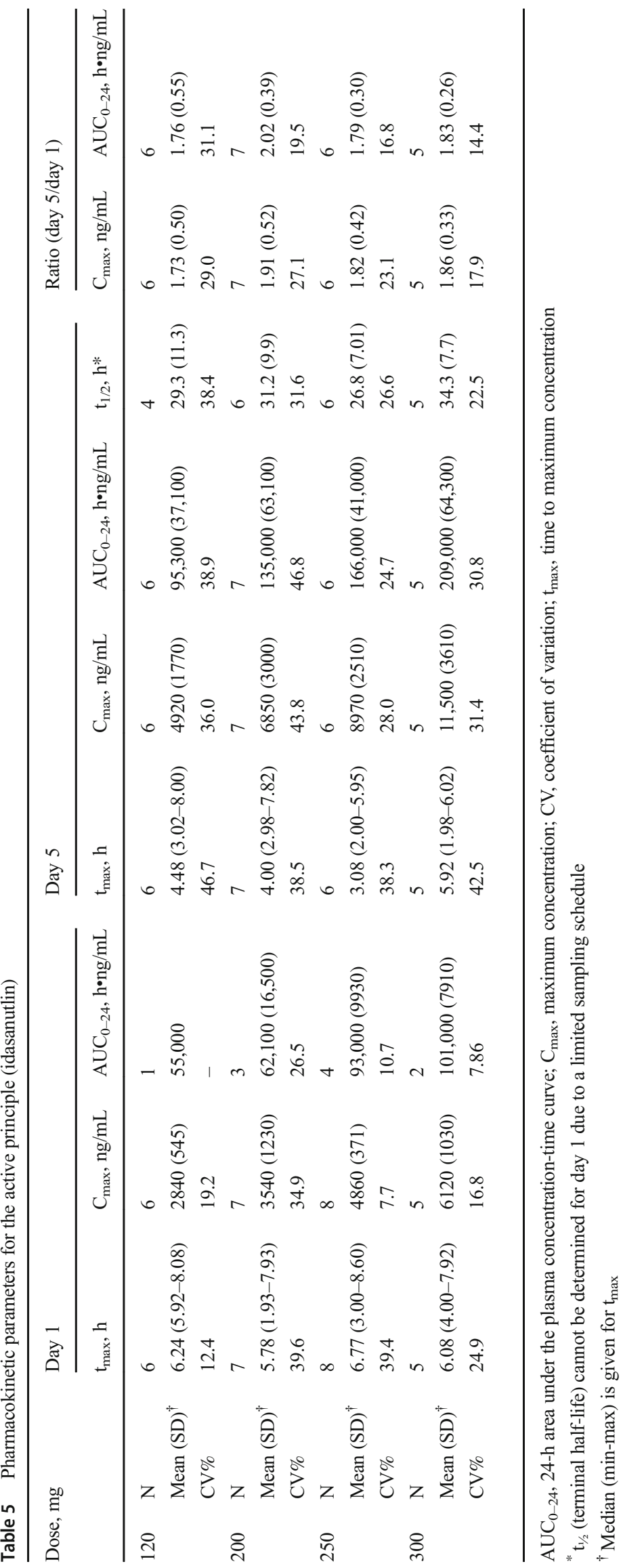


Fig. 2 Pharmacodynamic analyses. Association of MIC-1 (FCBL) levels with $\mathrm{AUC}_{24 \mathrm{~h}}$. AP, active principle; $\mathrm{AUC}_{24 \mathrm{~h}}, 24-\mathrm{h}$ area under the plasma concentration-time curve; FCBL, fold change from baseline; MIC1 , macrophage inhibitory cytokine 1

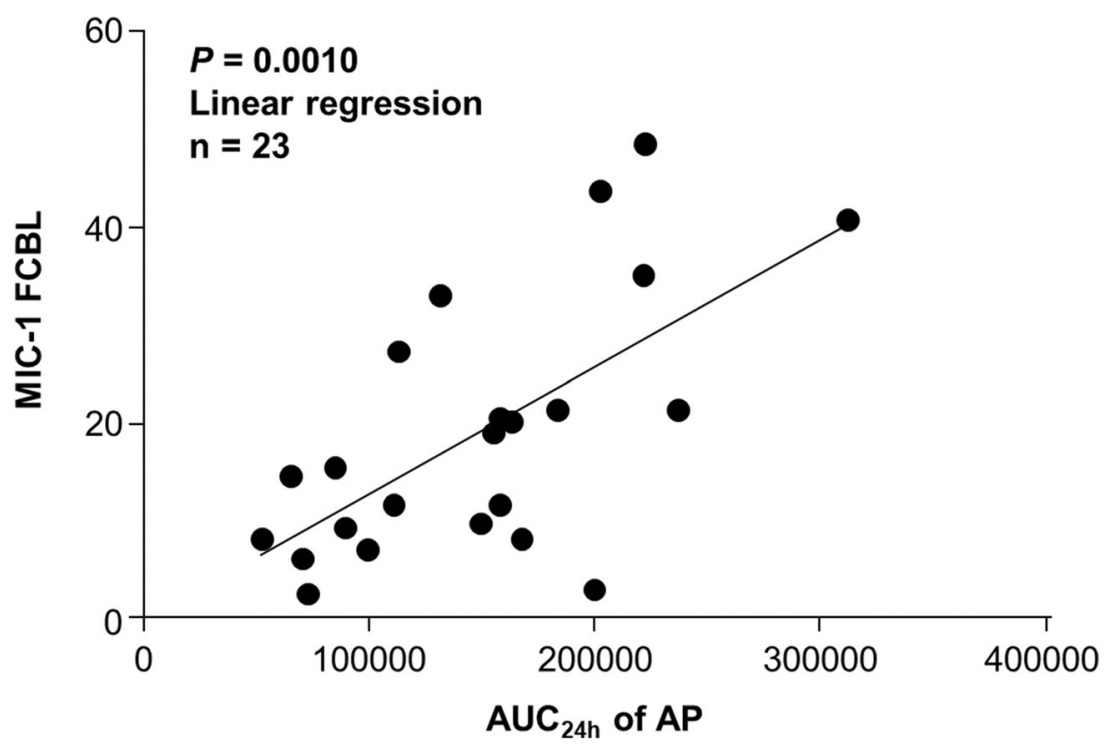

cannot swallow or absorb the oral compound. Pediatric oral formulations of idasanutlin are in development for clinical testing (NCT04029688). The prodrug RO6839921 was cleaved rapidly to release the AP in a dose-proportional manner and demonstrated significantly improved interpatient variability compared with oral idasanutlin in solid tumors $(27 \%$ vs $46 \% ; P=0.01)$. [17] In this study, RO6839921 also significantly improved interpatient variability of the AP compared with historical values for oral idasanutlin (33\% vs $48 \% ; P=0.01)$, although the difference was less pronounced than in solid tumors. [18] In addition, evidence of p53 activation by RO6839921 as measured by the increase in levels of the marker MIC-1 was associated with AP exposure. [9, 16]

RO6839921 was generally well tolerated, and its safety profile was consistent with that of oral idasanutlin. [8] The most common treatment-related AEs with RO6839921 were diarrhea, nausea, vomiting, decreased appetite, and fatigue. DLTs noted at doses of 300 and $250 \mathrm{mg}$ included QT interval prolongation, colitis, stomatitis, and diarrhea. By protocol definition, the MTD was $200 \mathrm{mg}$, with 0 of 7 patients having a DLT. However, in this population of patients with AML, a dose of up to $250 \mathrm{mg}$ could be considered tolerable since 2 of 8 patients $(25 \%)$ experienced DLT events of diarrhea and stomatitis.

Antileukemic activity (CR, CRi/MLFS, partial response, or HI/SD) was observed with RO6839921 in 11 of 26 patients, for a disease control rate of $42 \%$ and $\mathrm{CRc}$ rate of $8 \%$. Other compounds in the nutlin family have also showed efficacy in patients with AML (manuscript submitted, Lancet Haematol August 2019). RG7112 resulted in complete remissions in a phase 1 study in patients with relapsed/refractory AML. [12] Idasanutlin has also demonstrated significant clinical activity in a phase 1 study, with some CR durations lasting $>12$ months in patients with relapsed/refractory AML [8]; based on these results, a phase 3 study (MIRROS; NCT02545283) is ongoing in patients with relapsed or refractory AML treated with idasanutlin in combination with cytarabine vs placebo + cytarabine. [19]

\begin{tabular}{llllll}
\hline Response, $\mathrm{n}(\%)$ & $\begin{array}{l}120 \mathrm{mg} \mathrm{AP} \\
(n=6)\end{array}$ & $\begin{array}{l}200 \mathrm{mg} \mathrm{AP} \\
(n=7)\end{array}$ & $\begin{array}{l}250 \mathrm{mg} \mathrm{AP} \\
(n=8)\end{array}$ & $\begin{array}{l}300 \mathrm{mg} \text { AP } \\
(n=5)\end{array}$ & $\begin{array}{l}\text { Total } \\
(N=26)\end{array}$ \\
\hline $\mathrm{CR}$ & 0 & 0 & $1(12.5)$ & 0 & $1(3.8)$ \\
$\mathrm{CRp}$ & 0 & 0 & 0 & 0 & 0 \\
CRi/MLFS & 0 & 0 & 0 & $1(20.0)$ & $1(3.8)$ \\
Partial response & 0 & $1(14.3)$ & $1(12.5)$ & 0 & $2(7.7)$ \\
HI/SD & $2(33.3)$ & $2(28.6)$ & $2(25.0)$ & $1(20.0)$ & $7(26.9)$ \\
PD & $4(66.7)$ & $2(28.6)$ & $2(25.0)$ & $2(40.0)$ & $10(38.5)$ \\
Not evaluable/missing & 0 & $2(28.6)$ & $2(25.0)$ & $1(20.0)$ & $5(19.2)$ \\
\hline
\end{tabular}

$C R$ complete remission, $C R i$ complete remission with incomplete recovery of peripheral counts, $C R p$ complete remission without platelet recovery, $H I$ hematologic improvement, $M L F S$ morphological leukemia-free state, $P D$ progressive disease, $S D$ stable disease 
a

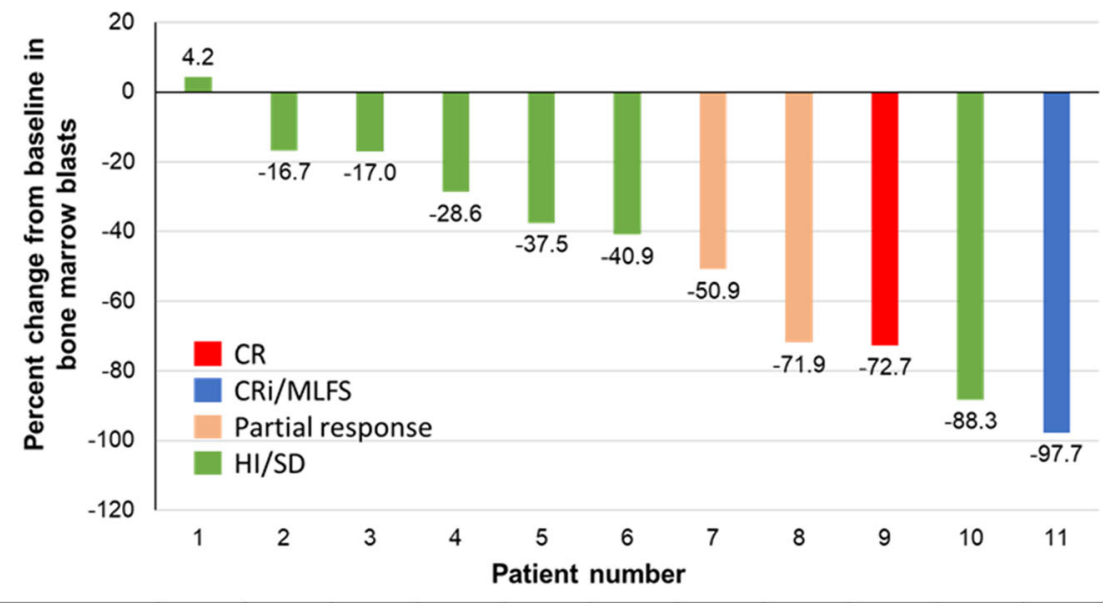

\begin{tabular}{|l|c|c|c|c|c|c|c|c|c|c|c|}
\hline AP dose, $\mathrm{mg}$ & 200 & 250 & 120 & 250 & 300 & 200 & 250 & 200 & 250 & 120 & 300 \\
\hline Blasts at baseline, \% & 48 & 30 & 53 & 42 & 88 & 88 & 22 & 89 & 11 & 18 & 87 \\
\hline Blasts at best response, $\%$ & 50 & 25 & 44 & 30 & 55 & 52 & 11 & 25 & 3 & 2 & 2 \\
\hline
\end{tabular}

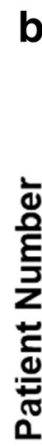

Fig. 3 Antileukemic activity. a Percent change from baseline in bone marrow blasts at best response in patients with antileukemic activity (CR, CRi/MLFS, PR, or HI/SD). b Response duration from treatment start in patients with antileukemic activity (CR, CRi/MLFS, partial response, or HI/SD). Patients without a symbol at the final study assessment
- HI/SD at $1^{\text {st }}$ non-PD assessment

- Partial response at $1^{\text {st }}$ non-PD assessment

- Cri/MLFS at $1^{\text {st }}$ non-PD assessment

- Cri/MLFS at very final study assessment
Overall, this phase 1 study showed that a soluble form of an MDM2 antagonist in the form of a pegylated prodrug to oral idasanutlin could be administered IV to patients with AML. The rapid cleavage of the prodrug RO6839921 to the AP (idasanutlin) accounts for the similar safety profile. Although RO6839921 demonstrated moderately improved variability compared with idasanutlin in patients with AML, [8] the data from this study, including those from the solid tumor arm [18], did not provide sufficient differentiation or improvement in the biologic or safety profile compared with oral idasanutlin to support continued development of the IV prodrug RO6839921.

Acknowledgments We thank the participants of the study and their families. Special thanks to Steven Middleton, Gwen Nichols, William Pierceall, Jianguo Zhi, Lori Jukofsky, Patricia Delora, David Stephen Ward, and Monica Reckner, and in memory of Zoran Filipovic.

Authorship All authors meet the International Committee of Medical Journal Editors (ICMJE) criteria for authorship for this article, take responsibility for the integrity of the work as a whole, the data and accuracy 
of the data analysis, and have given their approval for this version to be published. All authors had full access to all of the data in this study. All authors contributed substantially to the study design, the data analysis and interpretation, and the writing of the manuscript.

Funding This study was funded by F. Hoffmann-La Roche Ltd. The sponsor was responsible for the clinical operations oversight, data management, medical monitoring, drug supply, statistical analysis, drug safety process, medical writing, and journal article processing charges. All authors had full access to all of the data in this study and take complete responsibility for the integrity of the data and accuracy of the data analysis.

Data availability The datasets generated during and/or analyzed during the current study are available from the corresponding author on reasonable request. Qualified researchers may request access to individual patient level data through the ClinicalStudyDataRequest.com platform (www.clinicalstudydatarequest.com). Further details on Roche's criteria for eligible studies are available here (https://clinicalstudydatarequest. com/Study-Sponsors/Study-Sponsors-Roche.aspx). For further details on Roche's Global Policy on the Sharing of Clinical Information and how to request access to related clinical study documents, see here (https://www.roche.com/research_and_development/who_we_are_how we_work/clinical_trials/our_commitment_to_data_sharing.htm).

\section{Compliance with ethical standards}

Conflict of interest GLU has no conflicts of interest. SA received consultancy fees from Pfizer, Roche, Novartis, Janssen and AbbVie. A-MY, $\mathrm{SB}, \mathrm{BH}$ and L-CC were employed by Roche at the time of the study. KY received research funding from Astex, F. Hoffmann-LaRoche, MedImmune, Merck, Millennium and Roche/Genentech; honoraria from Novartis and Pfizer; and was a member of the Board of Directors or advisory committees for Astellas, Celgene, Novartis, Pfizer and Takeda.

Ethical approval All procedures performed in studies involving human participants were in accordance with the ethical standards of the institutional and/or national research committee and with the 1964 Helsinki Declaration and its later amendments or comparable ethical standards.

Informed consent Informed consent was obtained from all individual participants included in the study.

Open Access This article is licensed under a Creative Commons Attribution 4.0 International License, which permits use, sharing, adaptation, distribution and reproduction in any medium or format, as long as you give appropriate credit to the original author(s) and the source, provide a link to the Creative Commons licence, and indicate if changes were made. The images or other third party material in this article are included in the article's Creative Commons licence, unless indicated otherwise in a credit line to the material. If material is not included in the article's Creative Commons licence and your intended use is not permitted by statutory regulation or exceeds the permitted use, you will need to obtain permission directly from the copyright holder. To view a copy of this licence, visit http://creativecommons.org/licenses/by/4.0/.

\section{References}

1. Vassilev LT (2007) MDM2 inhibitors for cancer therapy. Trends Mol Med 13(1):23-31
2. Ozaki T, Nakagawara A (2011) Role of p53 in cell death and human cancers. Cancers (Basel) 3(1):994-1013

3. Nag S, Qin J, Srivenugopal KS, Wang M, Zhang R (2013) The MDM2-p53 pathway revisited. J Biomed Res 27(4):254-271

4. Cancer Genome Atlas Research Network, Ley TJ, Miller C, Ding L, Raphael BJ, Mungall AJ, Robertson A, Hoadley K, Triche TJ, Laird PW, Baty JD, Fulton LL, Fulton R, Heath SE, Kalicki-Veizer J, Kandoth C, Klco JM, Koboldt DC, Kanchi KL, Kulkarni S, Lamprecht TL, Larson DE, Lin L, Lu C, MD ML, JF MM, Payton J, Schmidt H, Spencer DH, Tomasson MH, Wallis JW, Wartman LD, Watson MA, Welch J, Wendl MC, Ally A, Balasundaram M, Birol I, Butterfield Y, Chiu R, Chu A, Chuah E, Chun HJ, Corbett R, Dhalla N, Guin R, He A, Hirst C, Hirst M, Holt RA, Jones S, Karsan A, Lee D, Li HI, Marra MA, Mayo M, Moore RA, Mungall K, Parker J, Pleasance E, Plettner P, Schein J, Stoll D, Swanson L, Tam A, Thiessen N, Varhol R, Wye N, Zhao Y, Gabriel S, Getz G, Sougnez C, Zou L, Leiserson MD, Vandin F, Wu HT, Applebaum F, Baylin SB, Akbani R, Broom BM, Chen K, Motter TC, Nguyen K, Weinstein JN, Zhang N, Ferguson ML, Adams C, Black A, Bowen J, Gastier-Foster J, Grossman T, Lichtenberg T, Wise L, Davidsen T, Demchok JA, Shaw KR, Sheth M, Sofia HJ, Yang L, Downing JR, Eley G (2013) Genomic and epigenomic landscapes of adult de novo acute myeloid leukemia. N Engl J Med 368(22):2059-2074

5. Quintás-Cardama A, Hu C, Qutub A, Qiu YH, Zhang X, Post SM, Zhang N, Coombes K, Kornblau SM (2017) p53 pathway dysfunction is highly prevalent in acute myeloid leukemia independent of TP53 mutational status. Leukemia 31(6):1296-1305

6. Ding Q, Zhang Z, Liu JJ, Jiang N, Zhang J, Ross TM, Chu XJ, Bartkovitz D, Podlaski F, Janson C, Tovar C, Filipovic ZM, Higgins B, Glenn K, Packman K, Vassilev LT, Graves B (2013) Discovery of RG7388, a potent and selective p53-MDM2 inhibitor in clinical development. J Med Chem 56(14):5979-5983

7. Vassilev LT, Vu BT, Graves B, Carvajal D, Podlaski F, Filipovic Z, Kong N, Kammlott U, Lukacs C, Klein C, Fotouhi N, Liu EA (2004) In vivo activation of the p53 pathway by small-molecule antagonists of MDM2. Science 303(5659):844-848

8. Yee K, Martinelli G, Vey N, Dickinson MJ, Seiter K, Assouline S, Drummond M, Yoon S-S, Kasner M, Lee J-H, Kelly KR, Blotner S, Higgins B, Middleton S, Nichols G, Chen G, Zhong H, Pierceall WE, Zhi J, Chen L-C (2014) Phase 1/1b study of RG7388, a potent MDM2 antagonist, in acute Myelogenous leukemia (AML) patients (Pts) (abstract). Blood 124(21):116

9. Siu LL, Italiano AI, Miller WH, Blay J-Y, Gietema JA, Bang Y-J, Mileshkin LR, Hirte HW, Reckner M, Higgins B, Jukofsky L, Blotner S, Zhi J, Middleton S, Nichols GL, Chen LC (2014) Phase 1 dose escalation, food effect, and biomarker study of RG7388, a more potent second-generation MDM2 antagonist, in patients (pts) with solid tumors (abstract 2535). J Clin Oncol 32(15 suppl):2535

10. Zhong H, Chen G, Jukofsky L, Geho D, Han SW, Birzele F, Bader S, Himmelein L, Cai J, Albertyn Z, Rothe M, Essioux L, Burtscher H, Middleton SA, Rueger R, Chen LC, Dangl M, Nichols G, Pierceall WE (2015) MDM2 antagonist clinical response association with a gene expression signature in acute myeloid leukaemia. Br J Haematol 171(3):432-435

11. Reis B, Jukofsky L, Chen G, Martinelli G, Zhong H, So WV, Dickinson MJ, Drummond M, Assouline S, Hashemyan M, Theron M, Blotner S, Lee JH, Kasner M, Yoon SS, Rueger R, Seiter K, Middleton SA, Kelly KR, Vey N, Yee K, Nichols G, Chen LC, Pierceall WE (2016) Acute myeloid leukemia patients' clinical response to idasanutlin (RG7388) is associated with pre-treatment MDM2 protein expression in leukemic blasts. Haematologica 101(5):e185-e188

12. Andreeff M, Kelly KR, Yee K, Assouline S, Strair R, Popplewell L, Bowen D, Martinelli G, Drummond MW, Vyas P, Kirschbaum M, Iyer SP, Ruvolo V, González GM, Huang X, Chen G, Graves B, 
Blotner S, Bridge P, Jukofsky L, Middleton S, Reckner M, Rueger R, Zhi J, Nichols G, Kojima K (2016) Results of the phase I trial of RG7112, a small-molecule MDM2 antagonist in leukemia. Clin Cancer Res 22(4):868-876

13. Higgins B, Tovar C, Glen K, Railkar A, Filipovic Z, Qureshi F, Vu B, Ehrlich G, Fishlock D, Chen L-C, Middleton S, Nichols G, Packman K, Vassilev L (2014) Preclinical activity of MDM2 antagonist RO6839921, a pegylated prodrug for intravenous administration (abstract A156). Mol Cancer Ther 14(12 Supplement 2):A156

14. Döhner H, Estey EH, Amadori S, Appelbaum FR, Büchner T, Burnett AK, Dombret H, Fenaux P, Grimwade D, Larson RA, Lo-Coco F, Naoe T, Niederwieser D, Ossenkoppele GJ, Sanz MA, Sierra J, Tallman MS, Löwenberg B, Bloomfield CD, LeukemiaNet E (2010) Diagnosis and management of acute myeloid leukemia in adults: recommendations from an international expert panel, on behalf of the European LeukemiaNet. Blood 115(3):453-474

15. Skolnik JM, Barrett JS, Jayaraman B, Patel D, Adamson PC (2008) Shortening the timeline of pediatric phase I trials: the rolling six design. J Clin Oncol 26(2):190-195

16. Yang H, Filipovic Z, Brown D, Breit SN, Vassilev LT (2003) Macrophage inhibitory cytokine-1: a novel biomarker for $\mathrm{p} 53$ pathway activation. Mol Cancer Ther 2(10):1023-1029
17. Razak A, Gore L, Britten CD, Miller WH, Uy GL, Nichols G, Middleton S, Blotner S, Zhi J, Jukofsky L, Pierceall W, Higgins B, Chen LC (2016) A phase I study of the MDM2 antagonist RO6839921, a pegylated prodrug of idasanutlin, for intravenous (IV) administration in patients with advanced solid tumors (abstract). Eur J Cancer 69:S21-S22

18. Abdul Razak AR, Miller WH, Uy GL, Blotner S, Young AM, Higgins B, Chen LC, Gore L (2019) A phase 1 study of the MDM2 antagonist RO6839921, a pegylated prodrug of idasanutlin, in patients with advanced solid tumors. Invest New Drugs. [Epub ahead of print] doi: https://doi.org/10.1007/s10637-019-00869-2

19. Montesinos P, Esteve J, Konopleva M, Martinelli G, Ottmann O, Rodriguez-Veiga R, Röllig C, Wei A, Vey N, Chiu I, Monnet A, Ott MG, Fenaux P (2019) MIRROS: An ongoing randomized phase 3 trial of idasanutlin + ARA-C in patients with relapsed or refractory acute myeloid leukemia (abstract). J Clin Oncol 37(15_suppl): TPS7063-TPS7063

Publisher's note Springer Nature remains neutral with regard to jurisdictional claims in published maps and institutional affiliations. 